\title{
Entrectinib for the treatment of metastatic NSCLC: safety and efficacy
}

Andrea Sartore-Bianchi, Elio Gregory Pizzutilo, Giovanna Marrapese, Federica Tosi, Giulio Cerea \& Salvatore Siena

To cite this article: Andrea Sartore-Bianchi, Elio Gregory Pizzutilo, Giovanna Marrapese, Federica Tosi, Giulio Cerea \& Salvatore Siena (2020): Entrectinib for the treatment of metastatic NSCLC: safety and efficacy, Expert Review of Anticancer Therapy, DOI: 10.1080/14737140.2020.1747439

To link to this article: https://doi.org/10.1080/14737140.2020.1747439

Accepted author version posted online: 28 Mar 2020.

Submit your article to this journal $₫$

山 Article views: 19

Q View related articles $₫$

View Crossmark data 
Publisher: Taylor \& Francis \& Informa UK Limited, trading as Taylor \& Francis Group

Journal: Expert Review of Anticancer Therapy

DOI: $10.1080 / 14737140.2020 .1747439$

\section{Entrectinib for the treatment of metastatic NSCLC: safety and efficacy}

Andrea Sartore-Bianchi ${ }^{1,2 *}$, Elio Gregory Pizzutilo ${ }^{1,2}$, Giovanna Marrapese ${ }^{1}$, Federica Tosi ${ }^{1,2}$, Giulio Cerea ${ }^{1}$, and Salvatore Siena ${ }^{1,2}$

1. Niguarda Cancer Center, Grande Ospedale Metropolitano Niguarda, Milan, Italy

2. Università degli Studi di Milano, Department of Oncology and Hemato-Oncology, Milan, Italy

*Corresponding author: andrea.sartorebianchi@unimi.it 


\begin{abstract}
Introduction: Gene fusions are strong driver alterations in various cancers, increasingly diagnosed with multiple testing techniques. ROS1 fusions can be found in 1-2\% of non-small cell lung cancer (NSCLC) and several tyrosine kinase inhibitors (TKIs) have been tested in this oncogene-driven disease. NTRK fusions are characteristic of a few rare types of cancer, also infrequently seen in some common cancers including NSCLC. Entrectinib is a newer ROS1 and NTRK inhibitor developed across different tumour types harbouring rearrangements in these genes. Entrectinib was granted FDA accelerated approval in August 2019 for the treatment of ROS1+ NSCLC and NTRK-driven solid tumors.
\end{abstract}

Areas covered: This review covers the mechanism of action, safety, and efficacy of entrectinib in patients with metastatic NSCLC.

Expert opinion: Entrectinib is an orally bioavailable TKI of TrkA, TrkB, TrkC, and ROS1, with the ability to cross the blood-brain barrier. Entrectinib was effective and well-tolerated in patients harbouring ROS1- or NTRK-rearranged NSCLC treated within phase I and II studies. Entrectinib appears to be the most appropriate treatment choice for TKIs-naïve patients, especially in those presenting brain metastasis. Conversely, in case of systemic progression with the evidence of acquired resistance mutations in ROS1 or Trk proteins, a sequential therapy with entrectinib could not be successful.

Keywords: Entrectinib; Lung Cancer; NSCLC; NTRK; ROS1; Rozlytrek; Targeted Therapy 


\section{Article highlights:}

- ROS1 fusions can be found in 1-2\% of non-small-cell lung cancers (NSCLCS), but they are enriched among younger and never-smokers patients.

- NTRK fusions interest less than $0.5 \%$ of all NSCLCs, and about $3 \%$ of cases with no other driver oncogenes.

- Entrectinib is a potent orally bioavailable tyrosine kinase inhibitor of TrkA, TrkB, TrkC, and ROS1, with the ability to cross the blood-brain barrier (BBB).

- Entrectinib encompasses higher intracranial activity than crizotinib, with similar duration of response and manageable toxicity profile and can be an alternative first-line treatment for patients with ROS1-rearranged NSCLC.

- Entrectinib demonstrated high response rate and durable response in patients affected by NTRKrearranged tumours, including NSCLC.

- Because of the capability of entrectinib to cross the BBB and the neurophysiological function of Trk receptors, peculiar side-effects mediated by Trk inhibition should be monitored (including cognitive impairment, increased appetite or dizziness).

- Entrectinib is an appropriate treatment choice for TKIs-naïve patients with ROS1 or NTRK-positive NSCLC, while evidences of activity against the most frequent acquired mutations related to TKIresistance are lacking. 


\section{Introduction}

Lung cancer is the most commonly diagnosed cancer and the leading cause of cancer-related mortality worldwide [1], with approximately 180,000 expected deaths in the European Union in 2019 [2] and 150,000 in the United States, a quarter of all deaths from cancer [3] . Age-standardized incidence rate in developed countries is 19.1 per 100,000 among females and reaches 40.4 per 100,000 in males [1]. Tobacco control efforts have decreased and will continue to decrease smoking-related lung cancer rates, hence an increase in the proportion of people who have never smoked is expected among the population with lung cancer in the future [4].

On the other hand, treatment opportunities for patients with lung cancer have tremendously evolved in the last decade. The American Lung Association reported an increase of the 5 -year survival rate from $17.2 \%$ in 2009 to $21.7 \%$ in 2019 in United States [5]. Both the detection of genetic drivers of oncogenesis suitable for pharmacological blockade and the discovery of immune-checkpoint inhibitors as new weapons against cancer have brought to reshape the treatment algorithms for non-small cell lung cancer (NSCLC), the most prevalent type of lung cancer.

The identification of the EGFR gene mutation as a potential target in NSCLC has only been the first step toward the age of targeted therapy. Numerous additional driver mutations amenable to direct inhibition, especially in adenocarcinomas, have been recognized, making NSCLC a heterogeneous group of diseases and the most relevant example of precision oncology. Consequently, several effective molecular-targeted agents, acting as tyrosine kinase inhibitors (TKIs), have been developed for EGFR, ALK, ROS1, BRAF, NTRK1,2,3 genetic alterations. Additionally, a quantity of new molecules are under clinical evaluation as inhibitors of other driver oncogenes in lung cancer, such as RET, MET, HER2, NRG1, or KRAS. Targeted treatments may produce higher response rates, higher quality of life, and longer survival compared with traditional cytotoxic chemotherapies [6-8].

The proto-oncogene ROS1 (c-ros oncogene 1) is located on chromosome 6q22.1 and encodes a receptor tyrosine kinase (RTK) whose role has not been defined [9]. ROS1 gene rearrangements are found in 1-2\% of 
NSCLC [10] and they can involve diverse fusion partners. The tyrosine kinase domain is always preserved and its constitutive activation is thought to stimulate the PI3K/AKT/mTOR, JAK/STAT, and MAPK/ERK pathways, resulting in proliferative growth and cell survival [11]. Consequently, pharmacological blockade of ROS1 signalling was demonstrated to induce growth inhibition in cell lines and durable clinical response in patients with advanced ROS1-rearranged NSCLC [12]. ROS1 rearrangements are easier to be found among younger and never-smokers patients harbouring high grade adenocarcinomas of the lung [10]. Since March 2016, crizotinib has been the only TKI inhibitor approved by Food and Drug Administration (FDA) and European Medicines Agency (EMA) for the treatment of advanced ROS1-rearranged NSCLC.

Trk A, Trk B and Trk C are transmembrane kinases encoded by NTRK1 (1q21-q22), NTRK2 (9q22.1), and NTRK3 (15q25) genes, respectively. These receptors are the target of neurotrophins, which take part in development and function of the nervous system. Their activation lead to cellular proliferation and increasing survival driving a variety of downstream signalling pathways, including MAPK, PI3K and PKC [13]. A diversity of intrachromosomal or interchromosomal NTRK genes rearrangements has been described in several tumour types, and the originated chimeric oncoprotein presents a neurotrophin-independent constitutive activation of the Trk kinase $[13,14]$. NTRK1 gene fusions in NSCLC were firstly identified in 2012 by Vaishnavi et al. in a population of patients affected by lung adenocarcinomas with no other detectable oncogenes $(3 / 91 ; 3.3 \%)$ [15]. Overall, NTRK gene fusions can be found in less than $0.5 \%$ of NSCLC, linked with no peculiar clinicopathologic features [15-17]. Upon its rarity, a mass screening approach with next generation sequencing technology or rational diagnostic algorithms (e.g. screening of driver-negative NSCLC by means of immunohistochemistry, fluorescence in situ hybridisation, or reverse transcriptase polymerase chain reaction) are important in terms of practical and economic feasibility [18]. Entrectinib and Larotrectinib have been the first TKIs studied with the aim to block the oncogenic driving function of Trk kinases.

Entrectinib is a novel ROS1 and NTRK inhibitor approved by FDA for the treatment of ROS1-positive NSCLC and all NTRK-driven solid tumors. Here we reviewed its mechanism of action, safety, and efficacy in patients with metastatic NSCLC. 


\section{Overview of the market}

\subsection{ROS1 inhibition}

Crizotinib represents the standard treatment choice for patients affected by ROS1-rearranged NSCLC, since it is the first ROS1 inhibitor approved by both FDA and EMA and it is supported by the widest amount of evidences so far. Crizotinib demonstrated activity at nanomolar concentrations as inhibitor of MET, ALK and ROS1 in biochemical assays [19] and the Profile 1001 trial firstly evaluated its safety and clinical activity among patients with advanced ROS1-rearranged NSCLC [12]. The most updated data of Profile 1001 derive from results on 53 patients (87\% pre-treated) who received crizotinib, $250 \mathrm{mg}$ twice daily, with a median of follow-up period of 62.6 months in total. The overall response rate (ORR) was $72 \%$, with 24.7 months of median duration of response (mDOR), and the median progression free survival (mPFS) was 19.3 months $(95 \% \mathrm{Cl}, 15.2-39.1)$. The safety profile was favourable, even with longterm treatment, with most of treatment-related adverse events (TRAE) being grade 1 or 2 (mainly vision disorders, emesis and oedema) [8]. Similar results were obtained in other Asian, European and Italian phase II studies examining crizotinib in ROS1-rearranged NSCLC, where ORR was $72 \%, 70 \%$ and $65 \%$, and mPFS was 15.9, 20 and 22.8 months, respectively [20-22]. A fourth French study, with 37 patients, reported an ORR of $69.4 \%$ with a mPFS of 5.5 months. By the way, this study-population was more heavily pretreated, with ECOG PS 2 in $25 \%$ of patients versus 2\% in Profile 1001 [23]. A new "benchmark" of 51.4 months for median overall survival (mOS) was achieved by Profile 1001 study for patients with advanced ROS1-rearranged NSCLC [8]. An enhanced efficacy of pemetrexed-based chemotherapy in patients harbouring ROS1 fusions as driver oncogene $[24,25]$ could have contributed to this outcome. Otherwise, the activity of anti-PD1/PD-L1 directed immune-checkpoint-inhibitors seems to be poor in the subset of oncogene-addicted NSCLC, but limited data are available for patients harbouring ROS1-rearranged cancers [26]. On the basis of this amount of data, crizotinib is approved by regulatory agencies worldwide and both NCCN [27] and ESMO guidelines [28] recommend it as first treatment choice in ROS1-rearranged NSCLC.

Crizotinib clinical efficacy is limited by two main issues. First, as it happens for other oncogene-driven 
NSCLC, ROS1-rearranged lung cancers ultimately acquire mechanisms of resistance under the therapeutic pressure of crizotinib, leading to disease progression [29]. Such acquired resistance mechanisms can arise in the ROS1 kinase domain, where the ROS1 G2032R mutation is the most frequently observed, or they can involve "off-target" pathways [9]. Second, crizotinib has a reduced penetrance across the blood-brain barrier (BBB) [30], that could be an issue since brain metastases are a key reason of morbidity and mortality in patients with NSCLC [31]. No data on brain activity was reported in Profile 1001 trial. In a retrospective analysis of two trials evaluating crizotinib in the setting of $A L K$-rearranged NSCLC, Costa et al. reported a systemic ORR of $53 \%$ but an intracranial response rate of $18 \%$ and intracranial mDOR of 6.6 months among patient with untreated brain metastasis [32]. Taking into consideration these unmet needs, a number of next-generation TKIs with anti-ROS1 activity are under clinical development: cabozantinib, ceritinib, DS-6051b, entrectinib, lorlatinib, and repotrectinib (Table 1) [33-39]. Most of these new molecules have already demonstrated high capability to cross the BBB in humans. In a phase II study, ceritinib exhibited similar ORR and PFS as crizotinib among TKI-naïve patients, with $69 \%$ of patients requiring at least one dose reduction due to toxicity and high rate of serious adverse events [35]. In preclinical studies, ceritinib has been able to overcome the gatekeeper L2026M mutation, but no other ROS1 mutations [40]. In a phase I-II study, lorlatinib showed systemic and intracranial activity in patients with ROS1-positive NSCLC after crizotinib failure [38]. Lorlatinib already presented preclinical activity against different crizotinib-resistant mutations, including L2026M, S1986Y/F, D2033N $[9,41,42]$. On the other hand, lorlatinib exhibited limited clinical activity against G2032R [41], providing stable disease as best response [43]. ROS1 ${ }^{\mathrm{G2032R}}$ is the most common acquired mutation after crizotinib, preventing the drug access to the kinase domain. Both DS-6051b, a selective ROS1/NTRK inhibitor, and cabozantinib, a multikinase inhibitor, have shown activity against ROS1 ${ }^{\text {G2032R }}$ in preclinical models $[44,40]$. Repotrectinib, a new ROS1/TRK/ALK inhibitor, has been designed to overcome G2032R and has proven both preclinical and clinical activity [39, 45]. Among 5 patients with NSCLC harbouring ROS1 ${ }^{\mathrm{G} 2032 \mathrm{R}}$ treated in a dose-finding trial (TRIDENT-1), a tumor shrinkage was obtained in all cases using different doses of repotrectinib, with $40 \%$ of confirmed ORR [45]. 
Entrectinib enters as a new TKI in the crowded context of ROS1-driven NSCLC [46]. The NCCN guidelines indicate entrectinib as an alternative to crizotinib as first-line treatment option for ROS1-rearranged NSCLC, and ceritinib as second choice. Lorlatinib is recommended after progression on first-line TKI [27].

\subsection{NTRK inhibition}

Regarding NTRK-fusion positive cancers, larotrectinib and entrectinib have been the first drugs to be approved as inhibitors of Trk proteins, with tissue-agnostic criteria (Table 1). Larotrectinib is a highly selective pan-Trk inhibitor and has been tested in different tumour types of adult and paediatric patients, showing an ORR of $73 \%$ among adults. Toxicity were low, mostly grade $1-2$, with $9 \%$ of dose reduction and $<1 \%$ of discontinuation $[47,48]$. Data from 12 patients with TRK fusion-positive NSCLC were recently reported by Hong and colleagues: after a median follow-up of 12.9 months, ORR was $75 \%$ overall and $67 \%$ in 6 patients with brain metastases, with durable responses [48]. Larotrectinib is approved in US, Canada and Brazil. The European Medicines Agency (EMA) also recently recommended approval of larotrectinib for NTRK fusion-positive solid tumors [11].

Next generation Trk inhibitors are already under development with the aim to overcome the on-target resistance mechanisms developing under treatment with entrectinib or larotrectinib. As it happens for EGFR, ALK or ROS1 kinases, on-target acquired resistant mutations result in amino acid substitutions which sterically prevent the binding of the inhibitor drug. The analogous TrkA ${ }^{G 595 R}, \operatorname{TrkB}^{\mathrm{G639R}}$ and $\operatorname{TrkC}^{\mathrm{G623R}}$ are the most frequent mutations $[49,50]$. Two main agents specifically designed to best accommodate the Trk binding pocket in presence of these clinically observed resistance mutations are currently in development: selitrectinib (LOXO-195) and repotrectinib (TPX-0005) [39, 51]. Preliminary data, presented at the AACR 2019 meeting, showed an ORR of 50\% with selitrectinib in patients with acquired TrkA ${ }^{\text {G595R }}$, TrkB ${ }^{\text {G639R }}$ or TrkC ${ }^{G 623 R}$ mutations in different cancers. Tumor shrinkage was observed in $2 / 2$ evaluable patients with acquired mutations in the "gatekeeper" domain and in 1 out of 2 patients with mutations in DFG (Asp-Phe-Gly) motif of Trk protein, as well [52]. Repotrectinib led to partial responses in two patients with different tumors after progression to first-generation TKIs: a 
cholangiocarcinoma with acquisition of G595R and in trans-F589L mutations in NTRK1 after larotrectinib and a salivary gland tumor with G623R in NTRK3 after entrectinib [53].

\section{Introduction to the drug}

\subsection{Chemistry}

Entrectinib, previously known as NMS-E628 and then as RXDX-101, is a small molecule with a chemical structure of N-[5-(3,5-difluoro-benzyl)-1 H-indazol-3-yl]-4-(4-methyl-piperazin-1-yl)-2(tetrahydropyran-4-ylamino)-benzamide $\left(\mathrm{C}_{31} \mathrm{H}_{34} \mathrm{~F}_{2} \mathrm{~N}_{6} \mathrm{O}_{2}\right)$ in a specific cristalline form (WO2009/013126). The compound was synthesized and optimized at Nerviano Medical Sciences srl (NMS), Nerviano, Italy in 2008, firstly evaluated as an inhibitor of ALK kinase activity $[54,55]$.

\subsection{Pharmacodynamics}

Entrectinib is active as a multi-kinase inhibitor, more particularly of TrkA, TrkB, TrkC, ROS1 and ALK kinases, which share analogous amino-acidic sequences in their tyrosine kinase domain. Entrectinib behaves as a pure ATP competitor. The half maximal inhibitory concentration $\left(\mathrm{IC}_{50}\right)$ values for TrkA, TrkB, TrkC, ROS1 and ALK purified kinases are 1, 3, 5, 7 and $12 \mathrm{nM} / \mathrm{L}$, respectively [55, 56]. It has shown a higher potency than crizotinib against ALK [57]. In the setting of ROS1-driven cell lines, entrectinib results 40 -fold more potent than crizotinib [56]. Blocking of these deregulated receptor tirosine kinases (RTKs) results in inhibition of downstream oncogenic pathways [9, 13].

In the condition of crizotinib-resistant ROS1-rearranged NSCLC, the ROS1 kinase can acquire mutations which alter its conformation and the capability to bind the drug: ROS1 ${ }^{\mathrm{G} 2032 \mathrm{R}}$ (the most frequent), $\mathrm{ROS1}^{\mathrm{D2033R}}, \mathrm{ROS1}^{\mathrm{S1986Y/F}}$ (in the alfaC-helix of the kinase domain), ROS1 ${ }^{\mathrm{L2026M}}$ ("gatekeeper"), ROS1 $1^{\mathrm{L} 1951 \mathrm{R}}$ [9]. Entrectinib has failed to demonstrate activity in preclinical setting against ROS ${ }^{\mathrm{G} 2032 \mathrm{R}}$, conflicting data exist for ROS1 ${ }^{\text {L2026M }}$ and ROS1 ${ }^{\text {D2033N }}$, while entrectinib showed IC50 of $3.0 \mathrm{nM}$ in Ba/F3-CD74ROS1 $1^{\mathrm{L1951R}}$ cell lines $[44,56,58]$. ROS1 ${ }^{\mathrm{G} 2032 \mathrm{R}}$ mutation is analogous to $\operatorname{TrkA}^{\mathrm{G595R}}, \operatorname{TrkB}^{\mathrm{G} 639 \mathrm{R}}$ and $\operatorname{TrkC}^{\mathrm{G} 623 \mathrm{R}}$, that have been identified in patients with entrectinib-resistant NTRK-rearranged cancers $[49,50]$. The gatekeeper $\operatorname{ROS}^{12026 \mathrm{M}}$ 
mutation is analogous to TrkA ${ }^{\mathrm{F589L}}, \operatorname{TrkB}^{\mathrm{F} 633 \mathrm{~L}}$ and $\operatorname{TrkC}^{\mathrm{F} 617 \mathrm{~L}}$, also described after treatment with firstgeneration TKI in NTRK-rearranged cancers. Finally, acquired mutations in the DFG motif of Trk $\left(\operatorname{TrkA}{ }^{\mathrm{G667C}}, \operatorname{TrkB}^{\mathrm{G709C}}\right.$ and $\operatorname{TrkC}^{\mathrm{G} 696 \mathrm{~A}}$ ), which plays a role in regulation of kinase activity, have been reported after entrectinib or larotrectinib [52].

\subsection{Pharmacokinetics and metabolism}

Entrectinib is orally bioavailable (hard capsules) and has a systemic distribution, with the ability to cross the blood-brain barrier (BBB). Brain levels reach nearly $50 \%$ of plasma levels in mice [55]. The pharmacokinetic profile of entrectinib has been valued in two phase I studies $[37,59,60]$. Here we report the main findings:

- the identified recommended phase 2 dose (RP2D) is $600 \mathrm{mg}$ daily, with or without food;

- the estimated plasma half-life is $20-22$ hours, compatible with a once daily, continuous dosing regimen;

- the peak plasma concentration is reached from 2 to $4 \mathrm{~h}$ after administration (in the fed condition);

- entrectinib is highly bound by plasma proteins ( 99.5\%), with free-drug concentration 4-fold higher than that of trough concentrations observed in animal models with complete tumour inhibition;

- entrectinib is mainly metabolized by CYP3A4 (minor contribution from CYP2C9 and CYP1C19) to its active metabolite (M5) [61];

- steady state is achieved within one week for entrectinib and two weeks for M5 [61];

- entrectinib and M5 are mainly excreted in feces, with minimal excretion in urine (3\%) [61].

\section{Clinical efficacy}

\subsection{Phase I studies}

Entrectinib has been tested in two phase I trials, ALKA-372-001 (EudraCT 2012-000148-88; 2 sites, Italy) and STARTRK-1 (NCT02097810; 10 sites, United States, Korea, and Spain) [37]. Overall, 119 
patients with a median age of 55 years (18-80 years) were enrolled between 2012 and 2016 . The cohort of patients in studies harboured several solid tumour types (60\% NSCLC, 15\% gastro-intestinal cancers, $4 \%$ central nervous system cancers, and others), mostly heavily pretreated (in 25 cases even with ROS1 or ALK inhibitors). A half of them (60 patients) had a gene fusion involving NTRK1/2/3, ROS1, or $A L K$. The other 59 patients had point mutations, amplifications, copy number variants, insertions/deletions, or no alterations (in 6 cases) of $N T R K 1 / 2 / 3, R O S 1$, or $A L K$ genes. Responses by RECIST were observed exclusively in the sub-population of patients harbouring gene fusions with no history of prior TKI-treatment. Among 25 evaluable patients, one case of NSCLC with SQSTM1-NTRK1 fusion, 13 cases of NSCLC with ROS1 fusions and 4 cases of NSCLC with ALK fusions were included. 15 of these 18 patients (83\%) achieved a partial or complete response by RECIST. Entrectinib showed also intracranial activity, consistently with preclinical data, with one patient with NTRK1-rearranged NSCLC achieving intracranial complete response.

\subsection{Phase II studies}

The phase II STARTRK-2 basket trial (NCT02568267) is evaluating the activity of entrectinib in patients with advanced tumours harbouring NTRK1/2/3, ROS1, or ALK rearrangements. Integrated data from phase I and phase II trials evaluating entrectinib in ROS1 positive NSCLC and in NTRK positive solid tumors have been recently published in Lancet Oncology [62,63] (Table 1).

Overall, 53 patients with ROS1-fusion positive NSCLC have been treated with entrectinib as the first line TKI. As per blinded independent central review (BICR), the ORR was 77\% (95\% $\mathrm{Cl} 64-88)$ with $6 \%$ of complete responses (CR). The mDOR was 24.6 months ( $95 \% \mathrm{Cl} 11.4-34.8)$. The intracranial (IC) ORR was 55.0\% (95\% Cl 32-77) and median IC DOR was 12.9 mo (95\% Cl 5.6-not estimable) [62]. Ten patients with NTRK-fusion positive NSCLC have been treated with entrectinib. In this population, BICR ORR was $70.0 \%$ (95\% Cl 34.75-93.33) with $10.0 \%$ of CR. Four patients out of six with CNS secondary lesions achieved an intracranial response (2 complete, 2 partial) [63-65].

\section{Safety and tolerability}


Entrectinib toxicity profile is favourable. The most common treatment-emergent adverse events (AEs) are summarized in Table 2, compared with other Trk and ROS1 inhibitors available (Figure 1). Among 355 patients, treated with entrectinib regardless of molecular profile, age or cancer type, the most of AEs were grade 1-2, with dysgeusia occurring in $41 \%$ of patients, followed by fatigue, dizziness, nausea and diarrhea occurred (20-30\% of cases). Only one patient experienced a G4 AE (AST increase), while no grade 5 AEs were reported. Dose reductions and treatment discontinuation were necessary in $27 \%$ and $4 \%$ of the patients, respectively [63].

The broad spectrum of nervous system adverse reactions, including cognitive impairment, increased appetite, dizziness, or sleep disturbances, reflect the capability of entrectinib to cross the BBB and the role of Trk receptors in normal function of the nervous system. In particular, loss-of-function mutations in NTRK2 have been associated to loss of appetite control and obesity [13], therefore weight gain is a peculiar AE with Trk-inhibitors. With entrectinib, it is reported as G1-2 in 14\%, and G3 in $5 \%$ of patients. Elevation of creatinine levels is a side-effect unrelated to Trk inhibition which has been observed with entrectinib. Notably, entrectinib is thought to inhibit MATE1-mediated transport of creatinine [66], a mechanism already known with others TKIs [67], hence the rise of creatinine serum levels may not actually reflect a renal failure.

\section{Regulatory affairs}

Entrectinib received its first regulatory approval in Japan, by the Japanese Ministry of Health, Labour and Welfare (MHLW) in June 2019, for the treatment of adult and paediatric patients with NTRK-positive solid tumours, and it is under regulatory review for ROS1-positive NSCLC [68]. Entrectinib has been approved by FDA for treatment of ROS1 gene fusion-positive metastatic NSCLC and NTRK gene fusionpositive solid tumours in August 2019 [69]. Moreover, entrectinib is under regulatory review in European Union (Priority Medicines designation by EMA) for NTRK-positive solid tumours and ROS1positive NSCLC. 


\section{Conclusion}

The landscape of druggable molecular alterations of NSCLC has been relentlessly reshaping in recent years and includes now the low prevalence gene fusions of ROS1 or NTRK1/2/3. Entrectinib is an orally bioavailable tyrosine kinase inhibitor of TrkA, TrkB, TrkC, and ROS1, with the ability to cross the bloodbrain barrier. Results of two phase 1 trials (ALKA-372-001 and STARTRK-1) and of the phase II STARTRK-2 basket trial showed dramatic and durable responses, including high intracranial activity in patients with TKI-naïve tumours harbouring ROS1 or NTRK1/2/3 gene fusions. Entrectinib was overall well-tolerated and based on these studies received regulatory approval in Japan and USA and it is under regulatory review in European Union.

\section{Expert opinion}

Entrectinib enriches the therapeutic armamentarium for metastatic NSCLC by widening treatment options against ROS1-positive tumours and encompassing NTRK fusions into the spectrum of druggable alterations for this and other solid malignancies. Currently, crizotinib is the only ROS1 inhibitor approved by both FDA and EMA as a first-line treatment choice, but entrectinib is already approved in the US and Japan, and the EMA granted entrectinib Priority Medicine designation. Treatment with crizotinib is supported by a large amount of data, including long follow-up results and it is approved in 70 countries worldwide. Entrectinib can be an alternative first-line treatment for patients with ROS1-rearranged NSCLC based on its higher intracranial activity, similar duration of response and manageable toxicity profile, although side-effects mediated by Trk inhibition should be monitored. It must be considered that entrectinib has not the potential to overcome the most common resistance mutations acquired under crizotinib treatment, thus TKI-naïve patients could be the most appropriate population for therapy with entrectinib. In this setting, entrectinib should be the preferable choice for patients with brain metastasis, considering the lower capability of crizotinib to cross the BBB. In this way, the necessity of brain radiation therapy could be deferred or avoided, even more in the case of disseminated brain metastasis for which the toxicity on cognitive function of whole-brain radiation is more prominent, especially considering the extended survival of these patients [8]. In some 
circumstances, entrectinib could also be considered as a sequential TKI after crizotinib failure. The central nervous system is indeed a common first site of progression in patients who are taking crizotinib [31] and, in this situation when cerebral oligoprogression is diagnosed, a therapeutic switch to entrectinib could be considered based on the better capability of entrectinib to cross the BBB. In contrast, in case of systemic progression after crizotinib with evidence of secondary mutations in the ROS1 kinase domain, a sequential therapy with entrectinib should not be pursued. Other nextgeneration TKIs could be considered, taking into account that lorlatinib does not appear to overcome the most frequent mutation G2032R, while preliminary data with repotrectinib or DS-6051b against this resistance mechanism are promising (Figure 2).

Interestingly, no secondary mutations in the ROS1 kinase domain have been reported in cell models exposed to entrectinib, but acquisition of KRAS G12C mutation or amplification of KRAS and FGF3 [70], while clinical data are still lacking. Acquisition of KRAS G12C is an already reported mechanism of resistance to crizotinib [71], and it could be a potential therapeutic target of a new class of G12C inhibitors [72]. A combination of targeted therapy against ROS1 and KRAS G12C may be a potential strategy for overcoming crizotinib or entrectinib resistance in ROS1-rearranged NSCLC.

Entrectinib has also been approved in Japan and in the US by the FDA based on an agnostic indication, i.e. for solid tumours harbouring a chromosomal rearrangement involving NTRK genes, regardless of the histologic type of tumour. The EMA also granted entrectinib Priority Medicine designation for the treatment of NTRK fusion-positive tumours. NTRK fusions are very rare in NSCLC, but the increasing use of NGS panels with the support of rational diagnostic/prioritizing algorithms can facilitate their identification and clinical targeting. NCCN guidelines recommend entrectinib, as well as larotrectinib, as a first-line treatment choice for patients with any performance status affected by NTRK-positive NSCLC. Considering the available data based on short follow-up of a small number of patients with NSCLC treated with the two TKIs, and in absence of head-to-head comparison, no definitive conclusions can be taken about the best Trk inhibitor. Both of them demonstrated a high response rate with intracranial 
activity and a favourable safety profile. Similar mechanisms of resistance to entrectinib and larotrectinib have also been described within different tumor types, as well.

Comparably to ROS-1 driven tumors, next-generation Trk inhibitors with the ability to overcome acquired mutations are already under development. The subsequent important step will be to assess the efficacy of next-generation molecules, both ROS-1 and Trk inhibitors, in first-line setting. As already happened with osimertinib in the setting of EGFR-mutated NSCLC [73], the availability of more potent inhibitors will likely impact on the best treatment strategy (use in first-line vs sequencing) for these patients.

\section{Funding}

This paper was partially funded by Fondazione Oncologia Niguarda Onlus.

\section{Declaration of interest}

Andrea Sartore-Bianchi has served on the advisory board for Amgen, Bayer, Sanofi and Servier. Salvatore Siena has served on the advisory board for Amgen, Bayer, BMS, Sanofi, Celgene, Incyte, Merck, Novartis, Roche and Seattle Genetics. The authors have no other relevant affiliations or financial involvement with any organization or entity with a financial interest in or financial conflict with the subject matter or materials discussed in the manuscript apart from those disclosed.

\section{Reviewer disclosures}

One peer reviewer has attended editorial activities sponsored by Roche and Bristol Myers Squibb. Another reviewer has received funding for attending advisory boards by Genentech/Roche. Peer reviewers have no other relevant financial relationships or otherwise to disclose. 


\section{References}

Papers of special note have been highlighted as either of interest $(\bullet)$ or of considerable interest $(\bullet \bullet)$ to

readers.

1. Bray F, Ferlay J, Soerjomataram I et al. Global cancer statistics 2018: GLOBOCAN estimates of incidence and mortality worldwide for 36 cancers in 185 countries. CA. Cancer J. Clin. 2018; 68(6):394-424.

2. Malvezzi M, Carioli G, Bertuccio P et al. European cancer mortality predictions for the year 2019 with focus on breast cancer. Ann. Oncol. 2019; 30(5):781-787.

3. Siegel RL, Miller KD, Jemal A. Cancer statistics, 2019. CA. Cancer J. Clin. 2019; 69(1):7-34.

4. Jeon J, Holford TR, Levy DT et al. Smoking and Lung Cancer Mortality in the United States From 2015 to 2065: A Comparative Modeling Approach. Ann. Intern. Med. 2018; 169(10):684-693.

5. Key Findings | State of Lung Cancer | American Lung Association. [https://www.lung.org/ourinitiatives/research/monitoring-trends-in-lung-disease/state-of-lung-cancer/key-findings.html].

6. Kris MG, Johnson BE, Berry LD et al. Using multiplexed assays of oncogenic drivers in lung cancers to select targeted drugs. JAMA 2014; 311(19):1998-2006.

7. Solomon BJ, Kim D-W, Wu Y-L et al. Final Overall Survival Analysis From a Study Comparing First-Line Crizotinib Versus Chemotherapy in ALK-Mutation-Positive Non-Small-Cell Lung Cancer. J. Clin. Oncol. 2018; 36(22):2251-2258.

8. Shaw AT, Riely GJ, Bang Y-J et al. Crizotinib in ROS1-rearranged advanced non-small-cell lung cancer (NSCLC): updated results, including overall survival, from PROFILE 1001. Ann. Oncol. 2019; 30(7):11211126 .

9. Lin JJ, Shaw AT. Recent Advances in Targeting ROS1 in Lung Cancer. J. Thorac. Oncol. Off. Publ. Int. Assoc. Study Lung Cancer 2017; 12(11):1611-1625.

10. Bergethon K, Shaw AT, Ignatius Ou S-H et al. ROS1 Rearrangements Define a Unique Molecular Class of Lung Cancers. J. Clin. Oncol. 2012; 30(8):863-870.

11. Acquaviva J, Wong R, Charest A. The multifaceted roles of the receptor tyrosine kinase ROS in development and cancer. Biochim. Biophys. Acta 2009; 1795(1):37-52.

12. Shaw AT, Ou S-HI, Bang Y-J et al. Crizotinib in ROS1-rearranged non-small-cell lung cancer. N. Engl. J. Med. 2014; 371(21):1963-1971.

13. Amatu A, Sartore-Bianchi A, Bencardino K et al. Tropomyosin receptor kinase (TRK) biology and the role of NTRK gene fusions in cancer. Ann. Oncol. Off. J. Eur. Soc. Med. Oncol. 2019; 30(Supplement_8):viii5-viii15.

- Comprehensive review of NTRK fusions as agnostic biomarkers for cancer treatment

14. - Cocco E, Scaltriti M, Drilon A. NTRK fusion-positive cancers and TRK inhibitor therapy. Nat. Rev. Clin. Oncol. 2018; 15(12):731-747.

15. - Vaishnavi A, Capelletti M, Le AT et al. Oncogenic and drug-sensitive NTRK1 rearrangements in lung cancer. Nat. Med. 2013; 19(11):1469-1472. 
16. Farago AF, Le LP, Zheng $Z$ et al. Durable Clinical Response to Entrectinib in NTRK1-Rearranged NonSmall Cell Lung Cancer. J. Thorac. Oncol. Off. Publ. Int. Assoc. Study Lung Cancer 2015; 10(12):16701674.

17. Farago AF, Taylor MS, Doebele RC et al. Clinicopathologic Features of Non-Small-Cell Lung Cancer Harboring an NTRK Gene Fusion. JCO Precis. Oncol. 2018.

18. Solomon JP, Benayed R, Hechtman JF, Ladanyi M. Identifying patients with NTRK fusion cancer. Ann. Oncol. Off. J. Eur. Soc. Med. Oncol. 2019; 30(Supplement_8):viii16-viii22.

19. Shaw AT, Camidge DR, Engelman JA et al. Clinical activity of crizotinib in advanced non-small cell lung cancer (NSCLC) harboring ROS1 gene rearrangement. J. Clin. Oncol. 2012; 30(15_suppl):7508-7508.

20. Wu Y-L, Yang JC-H, Kim D-W et al. Phase II Study of Crizotinib in East Asian Patients With ROS1-Positive Advanced Non-Small-Cell Lung Cancer. J. Clin. Oncol. Off. J. Am. Soc. Clin. Oncol. 2018; 36(14):14051411.

21. Michels S, Massutí B, Schildhaus H-U et al. Safety and Efficacy of Crizotinib in Patients With Advanced or Metastatic ROS1-Rearranged Lung Cancer (EUCROSS): A European Phase II Clinical Trial. J. Thorac. Oncol. Off. Publ. Int. Assoc. Study Lung Cancer 2019; 14(7):1266-1276.

22. Landi L, Chiari R, Tiseo M et al. Crizotinib in MET-Deregulated or ROS1-Rearranged Pretreated NonSmall Cell Lung Cancer (METROS): A Phase II, Prospective, Multicenter, Two-Arms Trial. Clin. Cancer Res. Off. J. Am. Assoc. Cancer Res. 2019; 25(24):7312-7319.

23. Moro-Sibilot D, Cozic N, Pérol M et al. Crizotinib in C-MET- or ROS1-positive NSCLC: results of the AcSé phase II trial. Ann. Oncol. Off. J. Eur. Soc. Med. Oncol. 2019. doi:10.1093/annonc/mdz407.

24. Liang Y, Wakelee HA, Neal JW. Relationship of Driver Oncogenes to Long-Term Pemetrexed Response in Non--Small-Cell Lung Cancer. Clin. Lung Cancer 2015; 16(5):366-373.

25. Chen Y-F, Hsieh M-S, Wu S-G et al. Efficacy of Pemetrexed-Based Chemotherapy in Patients with ROS1 Fusion-Positive Lung Adenocarcinoma Compared with in Patients Harboring Other Driver Mutations in East Asian Populations. J. Thorac. Oncol. Off. Publ. Int. Assoc. Study Lung Cancer 2016; 11(7):11401152.

26. Mazières J, Drilon A, Lusque A et al. Immune checkpoint inhibitors for patients with advanced lung cancer and oncogenic driver alterations: results from the IMMUNOTARGET registry. Ann. Oncol. Off. J. Eur. Soc. Med. Oncol. 2019. doi:10.1093/annonc/mdz167.

27. National Comprehensive Cancer Network. NCCN Clinical Practice Guidelines in Oncology (NCCN Guidelines ${ }^{\circledR}$ ) for Non-Small Cell Lung Cancer (version 1.2020). Available from: https://www.nccn.org/ professionals/physician_gls/recently_updated.aspx. Accessed November 23, 2019. .

28. Planchard D, Popat S, Kerr K et al. Metastatic non-small cell lung cancer: ESMO Clinical Practice Guidelines for diagnosis, treatment and follow-up. Updated 18 September 2019. Available at: https://www.esmo.org/Guidelines/Lung-and-Chest-Tumours/Metastatic-Non-Small-Cell-Lung-Cancer. Accessed November 23, 2019. Ann. Oncol. Off. J. Eur. Soc. Med. Oncol. 2018; 29(Suppl 4):iv192-iv237.

29. Gainor JF, Tseng D, Yoda S et al. Patterns of Metastatic Spread and Mechanisms of Resistance to Crizotinib in ROS1-Positive Non-Small-Cell Lung Cancer. JCO Precis. Oncol. 2017. doi:10.1200/PO.17.00063. 
30. Costa DB, Kobayashi S, Pandya SS et al. CSF concentration of the anaplastic lymphoma kinase inhibitor crizotinib. J. Clin. Oncol. Off. J. Am. Soc. Clin. Oncol. 2011; 29(15):e443-445.

31. Patil T, Smith DE, Bunn PA et al. The Incidence of Brain Metastases in Stage IV ROS1-Rearranged NonSmall Cell Lung Cancer and Rate of Central Nervous System Progression on Crizotinib. J. Thorac. Oncol. Off. Publ. Int. Assoc. Study Lung Cancer 2018; 13(11):1717-1726.

32. Costa DB, Shaw AT, Ou S-HI et al. Clinical Experience With Crizotinib in Patients With Advanced ALKRearranged Non-Small-Cell Lung Cancer and Brain Metastases. J. Clin. Oncol. 2015; 33(17):1881-1888.

33. Drilon A, Somwar R, Wagner JP et al. A Novel Crizotinib-Resistant Solvent-Front Mutation Responsive to Cabozantinib Therapy in a Patient with ROS1-Rearranged Lung Cancer. Clin. Cancer Res. Off. J. Am. Assoc. Cancer Res. 2016; 22(10):2351-2358.

34. Sun TY, Niu X, Chakraborty A et al. Lengthy Progression-Free Survival and Intracranial Activity of Cabozantinib in Patients with Crizotinib and Ceritinib-Resistant ROS1-Positive Non-Small Cell Lung Cancer. J. Thorac. Oncol. Off. Publ. Int. Assoc. Study Lung Cancer 2019; 14(2):e21-e24.

35. Lim SM, Kim HR, Lee J-S et al. Open-Label, Multicenter, Phase II Study of Ceritinib in Patients With NonSmall-Cell Lung Cancer Harboring ROS1 Rearrangement. J. Clin. Oncol. Off. J. Am. Soc. Clin. Oncol. 2017; 35(23):2613-2618.

36. Fujiwara $\mathrm{Y}$, Takeda $\mathrm{M}$, Yamamoto $\mathrm{N}$ et al. Safety and pharmacokinetics of DS-6051b in Japanese patients with non-small cell lung cancer harboring ROS1 fusions: a phase I study. Oncotarget 2018; 9(34):23729-23737.

37. •- Drilon A, Siena S, Ou S-HI et al. Safety and Antitumor Activity of the Multitargeted Pan-TRK, ROS1, and ALK Inhibitor Entrectinib: Combined Results from Two Phase I Trials (ALKA-372-001 and STARTRK1). Cancer Discov. 2017; 7(4):400-409.

\section{-• First report of pooled phase 1 studies of entrectinib in patients with solid tumours harboring} molecular alterations of NTRK1-3, ROS1 or ALK genes.

38. Shaw AT, Solomon BJ, Chiari R et al. Lorlatinib in advanced ROS1-positive non-small-cell lung cancer: a multicentre, open-label, single-arm, phase 1-2 trial. Lancet Oncol. 2019. doi:10.1016/S14702045(19)30655-2.

39. Drilon A, Ou S-HI, Cho BC et al, Repotrectinib (TPX-0005) Is a Next-Generation ROS1/TRK/ALK Inhibitor That Potently Inhibits ROS1/TRK/ALK Solvent- Front Mutations. Cancer Discov. 2018; 8(10):1227-1236.

40. Katayama R, Kobayashi $Y$, Friboulet $L$ et al. Cabozantinib overcomes crizotinib resistance in ROS1 fusion positive cancer. Clin. Cancer Res. Off. J. Am. Assoc. Cancer Res. 2015; 21(1):166-174.

41. Facchinetti $F$, Loriot $Y$, Kuo M-S et al. Crizotinib-Resistant ROS1 Mutations Reveal a Predictive Kinase Inhibitor Sensitivity Model for ROS1- and ALK-Rearranged Lung Cancers. Clin. Cancer Res. Off. J. Am. Assoc. Cancer Res. 2016; 22(24):5983-5991.

42. Zou HY, Li Q, Engstrom LD et al. PF-06463922 is a potent and selective next-generation ROS1/ALK inhibitor capable of blocking crizotinib-resistant ROS1 mutations. Proc. Natl. Acad. Sci. U. S. A. 2015; 112(11):3493-3498.

43. Solomon BJ, Martini J-F, Ou S-HI et al. 1380PDEfficacy of lorlatinib in patients (pts) with ROS1-positive advanced non-small cell lung cancer (NSCLC) and ROS1 kinase domain mutations. Ann. Oncol. 2018. doi:10.1093/annonc/mdy292.003. 
44. Katayama R, Gong B, Togashi $\mathrm{N}$ et al. The new-generation selective ROS1/NTRK inhibitor DS-6051b overcomes crizotinib resistant ROS1-G2032R mutation in preclinical models. Nat. Commun. 2019; 10(1):3604.

45. Cho $B C$, Drilon $A E$, Doebele RC et al. Safety and preliminary clinical activity of repotrectinib in patients with advanced ROS1 fusion-positive non-small cell lung cancer (TRIDENT-1 study). J. Clin. Oncol. 2019; 37(15_suppl):9011-9011.

46. Facchinetti F, Friboulet L. Profile of entrectinib and its potential in the treatment of ROS1-positive NSCLC: evidence to date. Lung Cancer Targets Ther. 2019; 10:87-94.

47. Drilon A, Laetsch TW, Kummar S et al. Efficacy of Larotrectinib in TRK Fusion-Positive Cancers in Adults and Children. N. Engl. J. Med. 2018; 378(8):731-739.

48. •• Hong DS, DuBois SG, Kummar S et al. Larotrectinib in patients with TRK fusion-positive solid tumours: a pooled analysis of three phase $1 / 2$ clinical trials. Lancet Oncol. 2020. doi:10.1016/S14702045(19)30856-3.

49. - Russo M, Misale S, Wei G et al. Acquired Resistance to the TRK Inhibitor Entrectinib in Colorectal Cancer. Cancer Discov. 2016; 6(1):36-44.

50. - Drilon A, Li G, Dogan S et al. What hides behind the MASC: clinical response and acquired resistance to entrectinib after ETV6-NTRK3 identification in a mammary analogue secretory carcinoma (MASC). Ann. Oncol. Off. J. Eur. Soc. Med. Oncol. 2016; 27(5):920-926.

51. Drilon A, Nagasubramanian R, Blake JF et al. A Next-Generation TRK Kinase Inhibitor Overcomes Acquired Resistance to Prior TRK Kinase Inhibition in Patients with TRK Fusion-Positive Solid Tumors. Cancer Discov. 2017; 7(9):963-972.

52. Hyman D, Kummar S, Farago A et al. Abstract CT127: Phase I and expanded access experience of LOXO195 (BAY 2731954), a selective next-generation TRK inhibitor (TRKi). Cancer Res. 2019; 79(13 Supplement):CT127-CT127.

53. Drilon A, Zhai D, Deng $W$ et al. Abstract 442: Repotrectinib, a next generation TRK inhibitor, overcomes TRK resistance mutations including solvent front, gatekeeper and compound mutations. Cancer Res. 2019; 79(13 Supplement):442-442.

54. - Ardini E, Menichincheri M, Ponti CD et al. Abstract A243: Characterization of NMS-E628, a small molecule inhibitor of anaplastic lymphoma kinase with antitumor efficacy in ALK-dependent lymphoma and non-small cell lung cancer models. Mol. Cancer Ther. 2009; 8(12 Supplement):A244-A244.

55. - Menichincheri M, Ardini E, Magnaghi P et al. Discovery of Entrectinib: A New 3-Aminoindazole As a Potent Anaplastic Lymphoma Kinase (ALK), c-ros Oncogene 1 Kinase (ROS1), and Pan-Tropomyosin Receptor Kinases (Pan-TRKs) inhibitor. J. Med. Chem. 2016; 59(7):3392-3408.

56. $\bullet$ Ardini E, Menichincheri M, Banfi P et al. Entrectinib, a Pan-TRK, ROS1, and ALK Inhibitor with Activity in Multiple Molecularly Defined Cancer Indications. Mol. Cancer Ther. 2016; 15(4):628-639.

-• First data generated concerning preclinical characterization of entrectinib

57. Ardini $E$, Menichincheri $M$, Banfi $P$ et al. Abstract $A 232$ : In vitro and in vivo activity of NMS-E628 against ALK mutations resistant to Xalkori. Mol. Cancer Ther. 2011; 10(11 Supplement):A232-A232. 
58. Chong CR, Bahcall M, Capelletti M et al. Identification of Existing Drugs That Effectively Target NTRK1 and ROS1 Rearrangements in Lung Cancer. Clin. Cancer Res. Off. J. Am. Assoc. Cancer Res. 2017; 23(1):204-213.

59. - Patel MR, Bauer TM, Liu SV et al. STARTRK-1: Phase 1/2a study of entrectinib, an oral Pan-Trk, ROS1, and ALK inhibitor, in patients with advanced solid tumors with relevant molecular alterations. J. Clin. Oncol. 2015; 33(15_suppl):2596-2596.

60. De Braud FG, Pilla L, Niger M et al. Phase 1 open label, dose escalation study of RXDX101, an oral pantrk, ROS1, and ALK inhibitor, in patients with advanced solid tumors with relevant molecular alterations. J. Clin. Oncol. 2014; 32(15_suppl):2502-2502.

61. Roche. Rozlytrek (entrectinib) [package insert]. U.S. Food and Drug Administration website. 2019. https://www.accessdata.fda.gov/drugsatfda_docs/label/2019/212725s000lbl.pdf Accessed: November 11, 2019. .

62. $-D$ Drilon A, Siena S, Dziadziuszko R et al. Entrectinib in ROS1 fusion-positive non-small-cell lung cancer: integrated analysis of three phase 1-2 trials. Lancet Oncol. 2019. doi:10.1016/S1470-2045(19)30690-4.

-• Pooled analysis of phase 1-2 trials of entrectinib in patients with ROS1 fusion-positive NSCLC

63. $\bullet$ Doebele RC, Drilon A, Paz-Ares L et al. Entrectinib in patients with advanced or metastatic NTRK fusion-positive solid tumours: integrated analysis of three phase 1-2 trials. Lancet Oncol. 2019. doi:10.1016/S1470-2045(19)30691-6.

-• Pooled analysis of phase 1-2 trials of entrectinib in patients with NTRK fusion-positive solid tumours

64. Braud FGMD, Siena S, Barlesi F et al. 1488PDEntrectinib in locally advanced/metastatic ROS1 and NTRK fusion-positive non-small cell lung cancer (NSCLC): Updated integrated analysis of STARTRK-2, STARTRK-1 and ALKA-372-001. Ann. Oncol. 2019. doi:10.1093/annonc/mdz260.010.

65. - Doebele R, Paz-Ares L, Farago AF et al. Abstract CT131: Entrectinib in NTRK-fusion positive (NTRK-FP) non-small cell lung cancer (NSCLC): Integrated analysis of patients enrolled in three trials (STARTRK-2, STARTRK-1 and ALKA-372-001). Cancer Res. 2019; 79(13 Supplement):CT131-CT131.

66. Drilon A. TRK inhibitors in TRK fusion-positive cancers. Ann. Oncol. Off. J. Eur. Soc. Med. Oncol. 2019; 30(Supplement_8):viii23-viii30.

67. Omote S, Matsuoka N, Arakawa $\mathrm{H}$ et al. Effect of tyrosine kinase inhibitors on renal handling of creatinine by MATE1. Sci. Rep. 2018; 8(1):9237.

68. ESMO. Japan Becomes the First Country to Approve Entrectinib. Available from: https://www.esmo.org/Oncology-News/Japan- Becomes-the-First-Country-to-Approve-Entrectinib. Accessed November 17, 2019. [https://www.esmo.org/Oncology-News/Japan-Becomes-the-FirstCountry-to-Approve-Entrectinib].

69. FDA. FDA approves entrectinib for NTRK solid tumors and ROS-1 NSCLC. Available from: https://www.fda.gov/drugs/resources-infor mation-approved-drugs/fda-approves-entrectinib-ntrksolid-tumorsand- ros-1-nsclc. Accessed November 17, 2019. 2019.

70. Ku BM, Bae YH, Lee KY et al. Entrectinib resistance mechanisms in ROS1-rearranged non-small cell lung cancer. Invest. New Drugs 2019. doi:10.1007/s10637-019-00795-3. 
71. Doebele RC, Pilling AB, Aisner DL et al. Mechanisms of Resistance to Crizotinib in Patients with ALK Gene Rearranged Non-Small Cell Lung Cancer. Clin. Cancer Res. Off. J. Am. Assoc. Cancer Res. 2012; 18(5):1472-1482.

72. Lindsay CR, Blackhall FH. Direct Ras G12C inhibitors: crossing the rubicon. Br. J. Cancer 2019; 121(3):197-198.

73. Ramalingam SS, Vansteenkiste J, Planchard D et al. Overall Survival with Osimertinib in Untreated, EGFR-Mutated Advanced NSCLC. N. Engl. J. Med. 2020; 382(1):41-50.

74. Hong DS, Bauer TM, Lee JJ et al. Larotrectinib in adult patients with solid tumours: a multi-centre, open-label, phase I dose-escalation study. Ann. Oncol. Off. J. Eur. Soc. Med. Oncol. 2019; 30(2):325331.

75. Deng W, Zhai D, Zhang X et al. Abstract 1319: Repotrectinib, a new generation ROS1 inhibitor, is highly potent against fusion ROS1s and emerging resistance mutations. Cancer Res. 2019; 79(13 Supplement):1319-1319.

76. Solomon BJ, Mok T, Kim D-W et al. First-Line Crizotinib versus Chemotherapy in ALK-Positive Lung Cancer. N. Engl. J. Med. 2014; 371(23):2167-2177. 
FIGURE LEGEND

Figure 1. Synopsis of main adverse events with relative frequencies of different NTRK- or ROS1-targeted tyrosine kinase inhibitors.

Ref: $[12,35,38,45,47,62,73]$.

$*=$ not reported.

Figure 2. Activity of different tyrosine kinase inhibitors in second-line setting after crizotinib/entrectinib (ROS-1+ NSCLC) or entrectinib/larotrectinib (NTRK+ NSCLC) failure according to the molecular mechanisms of acquired resistance (secondary mutations) or the clinical evolution (CNS oligoprogression). Single check= positive/limited preclinical data; Double check=validation in clinical setting; ?= conflicting preclinical data; $X=$ negative data; $n d=$ no data available. Homologous acquired alterations in ROS1 and Trk proteins are displayed in the same column. CNS oligoPD = central nervous system oligo-progressive disease.

Ref: $[40,44,51-53,56,58,75]$. 


\begin{tabular}{|c|c|c|c|c|c|}
\hline \multicolumn{7}{|c|}{ ROS1 targeted therapies in TKI-naïve NSCLC } \\
\hline Drug & Entrectinib & Crizotinib & Ceritinib & Lorlatinib & Repotrectinib \\
\hline Ref. & Drilon $2019[62]$ & Shaw $2019[8]$ & Lim $2017[35]$ & Shaw $2019[38]$ & Cho 2019 [45] \\
\hline N & 53 & 53 & 30 & 21 & 11 \\
\hline ORR & $77 \%$ & $72 \%$ & $67 \%$ & $62 \%$ & $82 \%$ \\
\hline mDOR & $24.6 \mathrm{mo}$ & $24.7 \mathrm{mo}$ & $21.0 \mathrm{mo}$ & $25.3 \mathrm{mo}$ & $\mathrm{NE}$ \\
\hline mPFS & $19.0 \mathrm{mo}$ & $19.3 \mathrm{mo}$ & $19.3 \mathrm{mo}$ & $21 \mathrm{mo}$ & - \\
\hline IC ORR & $55 \%$ & - & $25 \%$ & $64 \%$ & $100 \%(3 / 3)$ \\
\hline
\end{tabular}

NTRK targeted therapies in TKI-naïve NSCLC

\begin{tabular}{|c|c|c|}
\hline Drug & Entrectinib & Larotrectinib \\
\hline Ref. & Doebele 2019 [63] & Hong 2020 [48] \\
\hline N & 10 & 12 \\
\hline ORR & $70 \%$ & $75 \%$ \\
\hline mDOR & NE & NE \\
\hline mPFS & $14.9 \mathrm{mo}$ & NE \\
\hline IC ORR & $67 \%(4 / 6)$ & - \\
\hline
\end{tabular}

Table 1. Summary table of results from different tyrosine kinase inhibitors in ROS1+ and

NTRK+ NSCLC. Abbreviations: N: number of patients; NSCLC: non-small-cell lung cancer;

Ref.: reference; -: data not available; ORR: overall response rate; IC: intracranic; mo: months;

mDOR: median duration of response; mPFS: median progression free survival; mOS: median

overall survival; NE: not estimable. 


\begin{tabular}{|c|c|c|c|}
\hline Drug & Entrectinib & Larotrectinib & Crizotinib \\
\hline Study & $\begin{array}{l}\text { ALKA, STARTRK-1, } \\
\text { STARTRK-2, } \\
\text { STARTRK-NG }\end{array}$ & $\begin{array}{l}\text { NCT02122913, } \\
\text { NAVIGATE }\end{array}$ & Profile 1014 \\
\hline Ref. & Doebele 2019 [63] & Hong 2019 [74] & Solomon 2014 [76] \\
\hline $\mathrm{N}$ & 355 & 125 & 171 \\
\hline $\begin{array}{l}\text { Most common } \\
(\geq 10 \%) \text { TEAEs } \\
\text { G1-2 }(\%)\end{array}$ & $\begin{array}{l}\text { Dysgeusia } 41 \\
\text { Fatigue } 25 \\
\text { Dizziness } 25 \\
\text { Constipation } 23 \\
\text { Diarrhea } 21 \\
\text { Nausea } 21 \\
\text { Paraesthesia } 19 \\
\text { Creatinine increase } 15 \\
\text { Myalgia } 15 \\
\text { Weight increase } 14 \\
\text { Oedema } 14 \\
\text { Vomiting } 14 \\
\text { Arthralgia } 12 \\
\text { AST increase } 10\end{array}$ & $\begin{array}{l}\text { Fatigue } 38 \\
\text { AST/ALT increase } 35 \\
\text { Dizziness } 30 \\
\text { Nausea } 29 \\
\text { Constipation } 26 \\
\text { Cough } 24 \\
\text { Dyspnoea } 20 \\
\text { Vomiting } 26 \\
\text { Diarrhea } 23 \\
\text { Oedema } 19 \\
\text { Anaemia } 17 \\
\text { Myalgia } 16 \\
\text { Pyrexia } 15 \\
\text { Weight increase } 16 \\
\text { Arthralgia } 14 \\
\text { Low appetite } 14 \\
\text { Dysgeusia } 13 \\
\text { Insomnia } 10 \\
\text { Memory impairment } 10 \\
\text { Paraesthesia } 10 \\
\end{array}$ & $\begin{array}{l}\text { Vision disorder } 70 \\
\text { Diarrhea } 59 \\
\text { Nausea } 55 \\
\text { Oedema } 48 \\
\text { Vomiting } 44 \\
\text { Constipation } 41 \\
\text { AST/ALT increase } 22 \\
\text { Fatigue 26 } \\
\text { Dysgeusia } 26 \\
\text { Dizziness } 18 \\
\text { Neutropenia } 10\end{array}$ \\
\hline $\begin{array}{l}\text { Most common } \\
(\geq 1 \%) \text { TEAEs G3 } \\
(\%)^{\wedge}\end{array}$ & $\begin{array}{l}\text { Weight increase } 5 \\
\text { Anaemia } 5 \\
\text { Fatigue } 3 \\
\text { Diarrhea } 1 \\
\text { AST increase } 1 * \\
\text { Arthralgia } 1 \\
\text { Myalgia } 1 \\
\text { Creatinine increase } 1 \\
\text { Dizziness } 1\end{array}$ & $\begin{array}{l}\text { Anaemia } 13 \\
\text { Fatigue } 5 \\
\text { AST/ALT increase } 6 \\
\text { Weight increase } 7 \\
\text { Neutropoenia } 7 \\
\text { Low appetite } 4 \mathrm{r} \\
\text { Dyspnoea 2 } \\
\text { Hypertension } 3 \\
\text { Nausea 2 } \\
\text { Pyrexia 2\# } \\
\text { Constipation } 1 \\
\text { Dizziness } 1 \\
\text { Diarrhea 1 }\end{array}$ & $\begin{array}{l}\text { AST/ALT increase } 14 \\
\text { Neutropenia } 11 \\
\text { Dyspnoea } 3 \\
\text { Fatigue } 3 \\
\text { QTc prolonged } 2 \\
\text { Anaemia 2 } \\
\text { Constipation } 2 \\
\text { Diarrhea } 2 \\
\text { Vomiting } 2 \\
\text { Nausea } 1 \\
\text { Vision disorder } 1 \\
\text { Oedema 1 }\end{array}$ \\
\hline $\begin{array}{l}\text { TEAEs leading to } \\
\text { dose reduction }\end{array}$ & $27 \%$ & $15 \%$ & NA \\
\hline $\begin{array}{l}\text { TEAEs leading to } \\
\text { permanent } \\
\text { discontinuation }\end{array}$ & $4 \%$ & 0 & $6 \%$ \\
\hline
\end{tabular}

Table 2. Main toxicities of entrectinib, larotrectinib, and crizotinib. Abbreviations.

TEAEs: treatment-emerging adverse events; G: grade; N: number; NA: data not available.

*= 1 pt with G4 AST increase. \#=2 pts with G4 pirexia. ${ }^{\wedge}=\mathrm{G} 3-\mathrm{G} 4$ for crizotinib. 
Figure 1

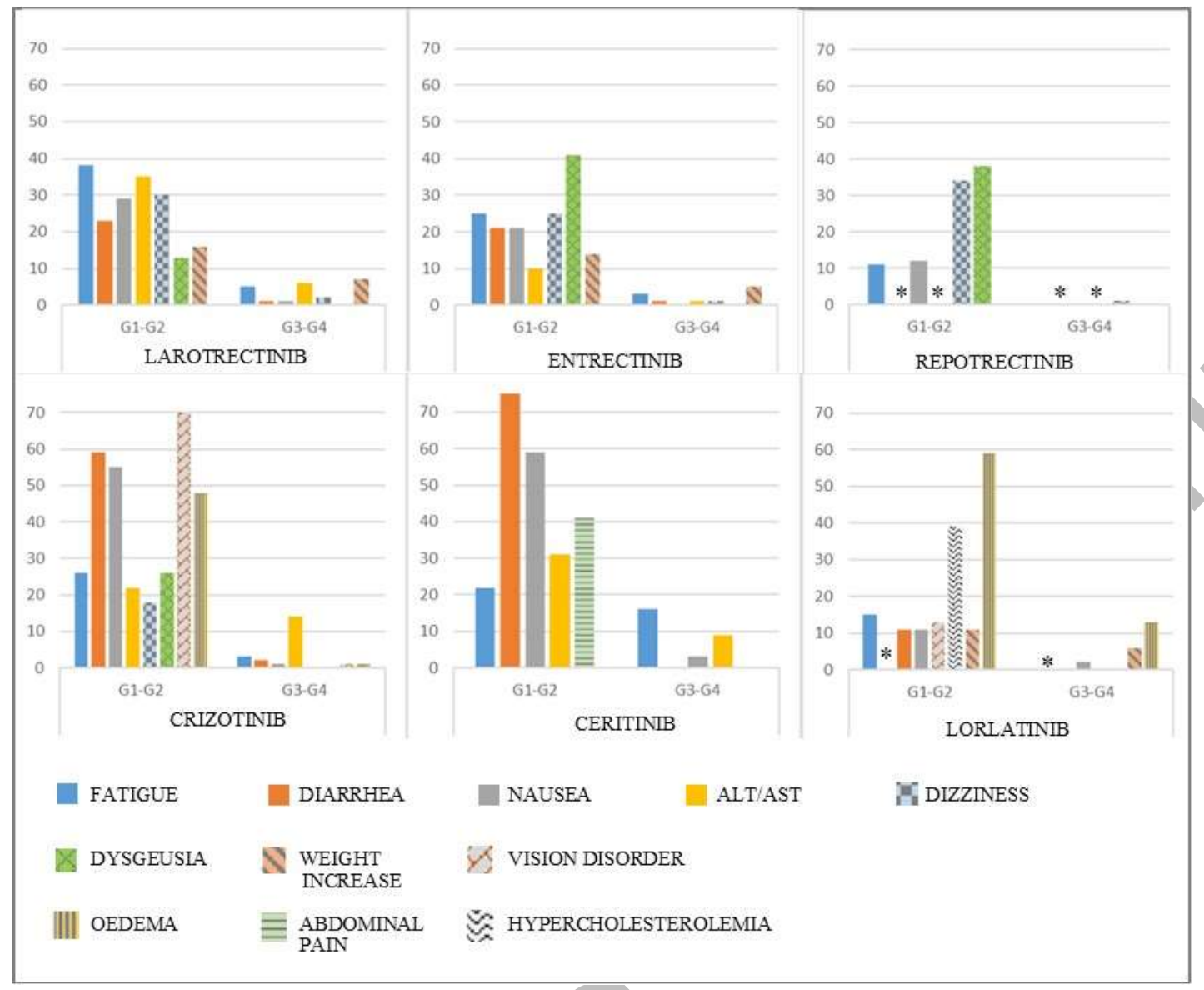


Figure 2

\begin{tabular}{|c|c|c|c|c|c|c|c|c|}
\hline \multirow{5}{*}{ 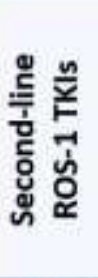 } & Entrectinib & 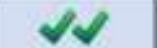 & $?$ & nd & $?$ & $x$ & $\checkmark$ & \\
\hline & Ceritinib & $\checkmark$ & $\checkmark$ & nd & x & $x$ & $x$ & \\
\hline & Lorlatinib & 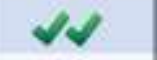 & $\vartheta$ & 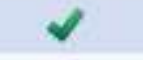 & $\checkmark$ & $x$ & $\checkmark$ & \\
\hline & Repotrectinib & $\checkmark$ & $\nu$ & $\vartheta$ & $\checkmark$ & $\checkmark$ & $\vartheta$ & \\
\hline & DS-6051b & $\checkmark$ & $\gamma$ & nd & $\checkmark$ & 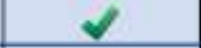 & $v$ & \\
\hline \multicolumn{2}{|c|}{$\begin{array}{l}\text { ROS-1: Reason for } \\
1^{\prime \prime} \text { line crizotinib or } \\
\text { entrectinib failure }\end{array}$} & $\begin{array}{c}\text { CNS } \\
\text { oligoPD to } \\
\text { crizotinib }\end{array}$ & $\begin{array}{l}\text { ROS1- } \\
\text { L2026M }\end{array}$ & $\begin{array}{c}\text { ROS1- } \\
\text { S1986Y/F }\end{array}$ & $\begin{array}{c}\text { ROS1- } \\
\text { D2033N }\end{array}$ & $\begin{array}{l}\text { ROS1- } \\
\text { G2032R }\end{array}$ & $\begin{array}{l}\text { ROS1- } \\
\text { L1951R }\end{array}$ & \\
\hline \multicolumn{2}{|c|}{$\begin{array}{l}\text { NTRK: Reason for } \\
1^{\circ} \text { line entrectinib or } \\
\text { larotrectinib failure }\end{array}$} & & $\begin{array}{l}\text { TrkA-F589L } \\
\text { TrkB-F633L } \\
\text { TrkC-F617L }\end{array}$ & & & $\begin{array}{c}\text { TrkA-G595R } \\
\text { TrkB-G639R } \\
\text { TrkC-G623R/E }\end{array}$ & & $\begin{array}{l}\text { TrkA-G667C } \\
\text { TrkB-G709C } \\
\text { TrkC-G696A }\end{array}$ \\
\hline \multirow{3}{*}{ 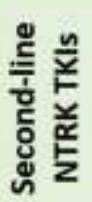 } & Selitrectinib & & 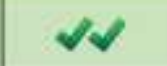 & & & $\infty$ & & $\checkmark$ \\
\hline & Repotrectinib & &  & & & $\checkmark$ & & $\bullet$ \\
\hline & DS-6051b & & nd & & & $\mathrm{x}$ & & X \\
\hline
\end{tabular}

